\title{
Gastrointestinal schwannoma: An unusual colonic lesion mimicking adenocarcinoma
}

\author{
Brent K Wilde MD FRCPC, Jenna-Lynn Senger, Rani Kanthan MBBS MS FRCS FRCPC FCAP MEd
}

BK Wilde, J-L Senger, R Kanthan. Gastrointestinal schwannoma: An unusual colonic lesion mimicking adenocarcinoma. Can J Gastroenterol 2010;24(4):233-236.

Gastrointestinal schwannoma is a rare, benign pathological entity that can mimic colonic adenocarcinoma and cause diagnostic dilemmas for treatment. A case of a 68-year-old woman with colonic adenocarcinoma who was discovered to have an incidental synchronous bowel lesion that proved to be a gastrointestinal schwannoma and not a synchronous adenocarcinoma is described. Gastrointestinal schwannomas are uncommon in the colorectal region; they are most often located in the stomach. These spindle cell lesions are distinct from gastrointestinal stromal tumours because the tumour cells have a distinct immunophenotype, with strong diffuse positivity for S-100, glial fibrillary acidic protein and vimentin, and corroborative negative staining of CD34, CD117 and smooth muscle markers. Accurate diagnosis and recognition of this benign entity is, therefore, of immense clinicopathological value for accurate planning of therapeutic strategies.

Key Words: Colonic adenocarcinoma; Gastrointestinal schwannoma; Nerve sheath myxoma

G astrointestinal schwannomas (GIS) are rare tumours of J the gastrointestinal tract. GIS are considered to be distinct entities from other nonepithelial tumours of the gastrointestinal tract, including leiomyoma, leiomyosarcoma, gastrointestinal autonomic neurogenic tumours (GANT) and gastrointestinal stromal tumours (GIST). Accurate recognition of colonic GIS, a benign neoplasm, is important because they often clinically mimic a malignant lesion. The following case presentation highlights this dilemma and discusses the salient pathological features supporting the diagnosis of GIS.

\section{CASE PRESENTATION}

A 68-year-old Caucasian woman presented with abdominal pain, weight loss, night sweats and episodic explosive diarrhea. The patient was in no acute distress and her abdomen was soft. There was localized tenderness in the infraumbilical area, where a large mass was palpable. Her medical history included a previous small bowel resection for a benign mesenteric pseudocyst and a total abdominal hysterectomy with bilateral salpingo-oophorectomy for fibroids. She had no other medical problems. Except for slight anemia, the remainder of the patient's laboratory investigations were unremarkable.

\section{Un schwannome gastro-intestinal : Une lésion colique inhabituelle imitant l'adénocarcinome}

\begin{abstract}
Le schwannome gastro-intestinal est une entité pathologique rare et bénigne qui peut imiter l'adénocarcinome colique et provoquer des dilemmes diagnostiques en matière de traitement. Les auteurs décrivent le cas d'une femme de 68 ans ayant un adénocarcinome colique chez qui on a découvert une lésion inflammatoire synchrone accessoire qui s'est révélée être un schwannome gastro-intestinal plutôt qu'un adénocarcinome synchrone. Les schwannomes gastro-intestinaux sont peu courants dans la région colorectale, mais sont surtout logés dans l'estomac. Ces lésions des cellules fusiformes sont distinctes des tumeurs stromales gastro-intestinales parce que les cellules tumorales ont un immunophénotype distinct, à la solide positivité diffuse à l'antiprotéine S-100, à la protéine acide fibrillaire gliale et à la vimentine, ainsi qu'une coloration négative corroborative du CD34, du CD117 et des marqueurs des muscles lisses. Il est donc d'une immense valeur clinicopathologique de parvenir à un diagnostic et un dépistage précis de cette entité bénigne pour bien planifier les stratégies thérapeutiques.
\end{abstract}

Department of Pathology, Royal University Hospital and Saskatoon Health Region, Saskatoon, Saskatchewan

Correspondence: Dr Rani Kanthan, Department of Pathology, Royal University Hospital and Saskatoon Health Region, 103 Hospital Drive,

Saskatoon, Saskatchewan S7N OW8. Telephone 306-655-2158, fax 306-655-2223, e-mail rani.kanthan@saskatoonhealthregion.ca

Received for publication July 7, 2009. Accepted July 8, 2009

\section{Investigations and therapy}

An ultrasound and computed tomography scan revealed a large solid colonic mass without evidence of distant abdominal and lung metastases. A subsequent colonoscopy revealed a large, partially obstructive stricture in the sigmoid colon, which proved to be a colonic adenocarcinoma on biopsy. Laparotomy with sigmoid colectomy was performed.

\section{Pathology}

\section{RESULTS}

The resection specimen contained a $16 \mathrm{~cm} \times 8 \mathrm{~cm} \times 3 \mathrm{~cm}$ mass located $15 \mathrm{~cm}$ from one of the surgical margins. Histological examination revealed an invasive colonic adenocarcinoma without lymph node involvement $\left(\mathrm{pT}_{3} ; \mathrm{pN}_{0}\right)$. Interestingly, a separate incidental lesion was identified $0.7 \mathrm{~cm}$ from one of the resection margins of the colon specimen. Grossly, this submucosal lesion consisted of a rubbery, white, rounded mass measuring $1.5 \mathrm{~cm}$ in diameter, with no identifiable necrosis or hemorrhage.

Histological examination of this nodule revealed a wellcircumscribed myxoid lesion, primarily submucosal and 


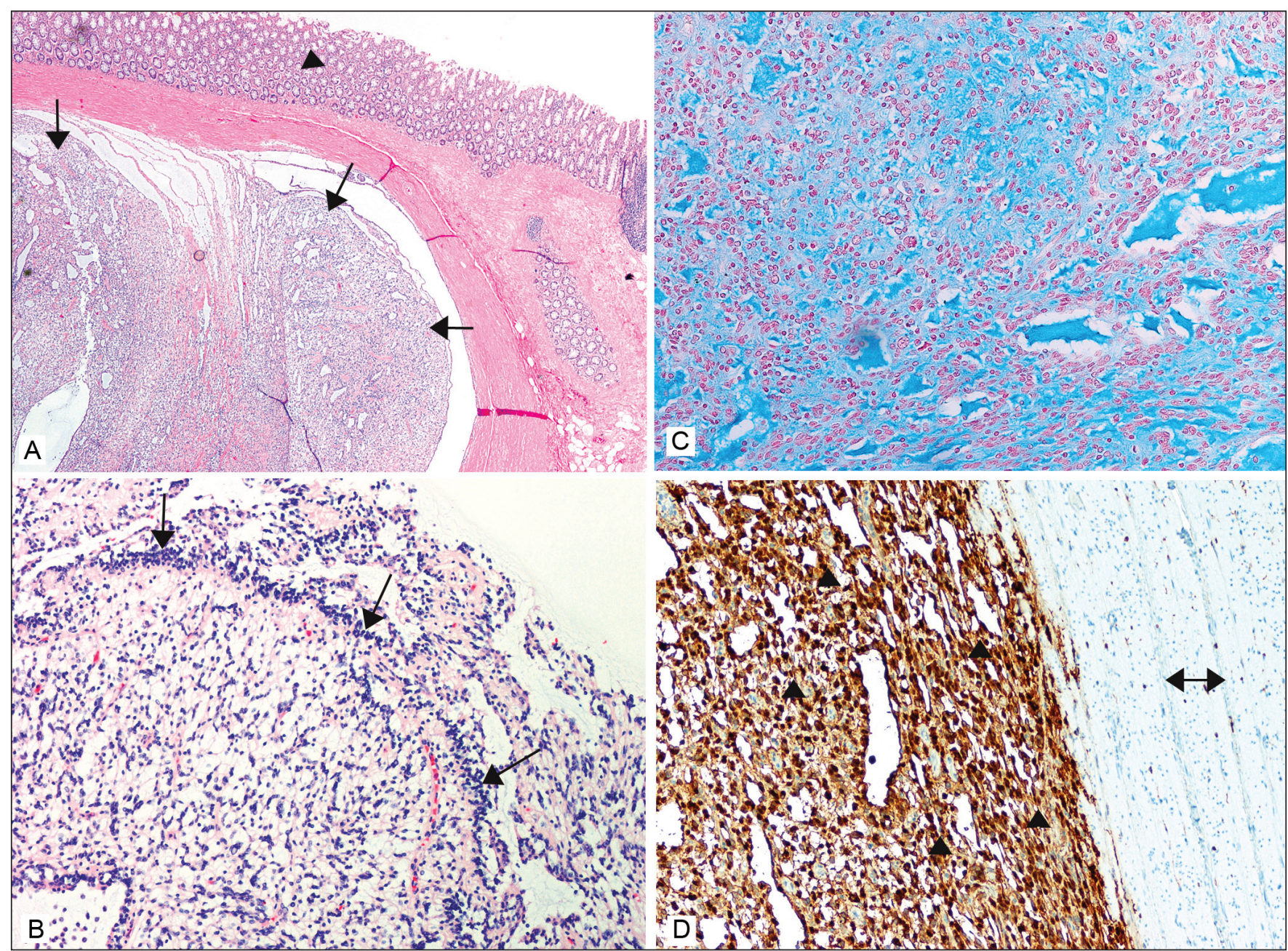

Figure 1) A Low-power examination showing the presence of a fairly well-demarcated submucosal neoplasm (arrows) with overlying intact colonic mucosa (arrowhead) (hematoxylin and eosin stain, original magnification $\times 75$ ). B Low-power examination showing a vague palisading pattern (arrows) in a loose hypocellular myxoid background (hematoxylin and eosin stain, original magnification $\times 75$ ). C Medium-power examination confirming strong positive staining (blue) of the myxoid stroma (alcian blue staining at pH 2.5 , original magnification $\times 250$ ). $\mathrm{D}$ Medium-power examination showing strong, diffuse positivity in the lesional cells (arrowheads) in contrast to the negative staining of the surrounding bowel wall (arrows) (immunohistochemical staining with S-100, original magnification $\times 250$ )

intramuscular in location, with intact overlying nondysplastic colonic epithelium (Figure 1A). There was an incomplete fibrous response surrounding the tumour. In the myxoid stroma, a vague, lace-like microcystic pattern was seen in areas, while in other areas the pattern was more solid. One area showed cellular condensation imparting a vaguely palisading pattern (Figure 1B). No prominent vascular pattern was seen. Occasionally, lymphocytes were seen but mast cells were absent. Tumour cells were quite uniform in appearance, having indistinct cellular margins, round to oval nuclei and fine chromatin with indistinct nucleoli. Mitotic figures were rare to absent. Fine reticulin staining was identified around individual cells. The myxoid stroma was strongly positive with alcian blue staining at $\mathrm{pH} 2.5$ (Figure 1C). Tumour cells exhibited strong diffuse positivity for S-100 (Figure 1D), glial fibrillary acidic protein and vimentin, but were negative for smooth muscle actin, CD34, CD117, desmin, HMB45, cytokeratin, synaptophysin, chromogranin and CD45. Immunohistochemistry for neurofilament protein showed a few small axonal fragments within the lesion. Based on the gross microscopic features and the immunohistochemical staining, this neoplasm was diagnosed as a benign GIS with extensive myxoid change.

\section{DISCUSSION}

Neurogenic tumours of the gastrointestinal tract most commonly arise from the Schwann cells of the nerve sheath $(1,2)$. GIS are rare, accounting for $2 \%$ to $6 \%$ of all stromal tumours of the gastrointestinal tract (1). According to the World Health Organization Classification of Tumours, GIS are classified as nonepithelial tumours of the stomach and colon/rectum, yet are considered to be a distinct, homogenous entity separate from leiomyoma, leiomyosarcoma, GANT and GIST $(3,4)$.

Most GIS occur in the stomach, but rare cases involving the colon, rectum and esophagus have been reported $(1,2,5)$. In decreasing frequency, they occur in the stomach, colorectum, esophagus and small intestine (6), while incidence in the colon occurs (in decreasing order) in the cecum, sigmoid, rectosigmoid, transverse colon and the descending colon and the rectum (7). The incidence is similar in both men and women, with a mean age in the sixth to seventh decade of life $(2,5)$. 
GIS are not associated with neurofibromatosis I or II, and most lack neurofibromatosis (NF) 1 and NF2 gene aberrations (8). However, in a case report by Fass et al (9), the benign retroperitoneal schwannoma that presented as colitis was reported to most likely have arisen because of a somatic mutation in the NF2 gene. Most often, these tumours present incidentally; however, occasionally they may cause symptoms including the presence of blood in stool, obstruction, defecation disorders and abdominal pain (10). At least one case, similar to our own, has documented the presence of a synchronous colonic adenocarcinoma (11).

GIS appear grossly as rubbery, well-circumscribed yellowwhite to tan ovoid nodules that are not encapsulated $(5,12)$ and ranging in size from $0.5 \mathrm{~cm}$ to $12 \mathrm{~cm}$ (mean $2.8 \mathrm{~cm}$ ) (6). They may protrude into the lumen and occasionally show overlying mucosal ulceration. Endoscopically, they appear as round, well-circumscribed, elevated submucosal masses, with intact overlying mucosa, in contrast to adenocarcinomas that are irregular and infiltrative, often containing one or more irregular areas of surface ulceration. These endoscopic findings of GIS have been particularly well documented with gastric schwannomas (13) rather than colonic schwannomas because the latter are extremely rare. Gross features often do not enable the distinction between schwannomas and GIST (6). Differentiation requires detailed histological evaluation to investigate characteristic features of schwannoma that include the presence of a lymphoid peripheral cuff with the absence of encapsulation and degenerative changes (14). It is believed that the lymphoid cuff is the result of cytokines secreted by the tumour cells, inducing chemokinesis of the lymphocytes (15).

Histologically, these moderately cellular neoplasms appear as interlacing woven nests or bundles of spindle cells. Multinodular patterns of growth have been recorded. GIS often have a prominently myxoid matrix that stains strongly positive with alcian blue at $\mathrm{pH} 2.5$ (12). GIS may show only vague rudimentary nuclear palisading and compact cell bundles, unlike the distinct Antoni A, Antoni B and Verocay bodies of soft tissue schwannomas $(3,5)$. Individual cells have eosinophilic cytoplasm without coarse fibrillar material or discernible cell walls. The nuclei are typically thinner than smooth muscle cell nuclei. Reticulin staining is noted around individual tumour cells. Most GIS show minimal or no mitotic activity (5). A common feature seen in many, but not all, cases of GIS is a peripheral cuff of B cell lymphoid aggregates (not identified in the present case) (1). This feature is typically not encountered in soft tissue schwannomas. The distinguishing microscopic morphology of GIS, in addition to the genetic evidence, supports the hypothesis that GIS are distinct from soft tissue schwannomas $(8,16)$.

Immunohistochemically, GIS show diffuse strong positivity for S-100 and vimentin, and variable positivity for glial fibrillary acidic protein, while they are typically negative for CD34, CD117, desmin, c-Kit and actin (1,4-7). This immunostaining pattern differentiates GIS from GIST, GANT and smooth muscle tumours of the gastrointestinal tract $(1,5,12)$. Immunohistochemically, although the majority of GIST show diffuse strong positivity for CD117 (c-Kit), up to 20\% of these tumours can be negative. In 2003, both Heinrich et al (17) and Hirota et al (18) found activating mutations in platelet-derived growth factor-alpha (PDGFRa), which is another class III tyrosine kinase. Mutations in c-Kit and PDGFRa appear to be alternative and mutually exclusive oncogenic mechanisms in GIST (17-19) probably representing the CD117-negative tumours.
Both GIS and GANT are believed to arise from Schwann cells of the intestinal wall enteric plexus, and some authors classify GIS as a category of GANT (11). GANT are bland tumours, made up of spindle cells or more epithelioid cells with fascicles, whorls or storiform areas. Most GANT express CD34 and CD117, while some express synaptophysin or neurofilament protein, and only approximately one-third express S-100 $(2,11)$. There is no reported case of GANT expressing glial fibrillary acidic protein (5).

Because GIS have a different prognosis than GANT and GIST, this is an important differentiation that warrants accurate recognition of GIS from these two entities. GIS, although benign in behaviour, can recur if excised incompletely and, on rare occasions, may undergo malignant degeneration if left untreated $(20,21)$. Rare cases of malignant gastric schwannoma have been reported in the literature (21). Such cases have a poor prognosis accompanied by a rapid clinical course and a poor response to chemotherapy, with an average life span of two years. In our case, the accurate identification of this lesion, although at the resection margin, negated the need for further surgical intervention because it was completely excised in the plane of the sections examined.

Another tumour having histological features similar to GIS is nerve sheath myxoma. Some authors even consider nerve sheath myxoma as a schwannoma subtype (16). It is a nonencapsulated, lobulated myxoid tumour that shows no Antoni A, Antoni B or Verocay body formation. This lesion is also believed to arise from Schwann cells, with a similar immunohistochemical staining pattern to GIS $(16,22)$. However, nerve sheath myxoma is typically dermal in location, with only rare reports of this lesion occurring at the mucous membranes (22). To date, nerve sheath myxomas of the gastrointestinal tract have not been reported in the published English literature. The current case may represent the first documented report of gastrointestinal nerve sheath myxoma occurring in the colorectal region because this lesion did display extensive myxoid change as a dominant histological feature.

GIS presents similarly to GIST and GANT, yet has a significantly different prognosis. Although gross inspection cannot yield conclusive findings regarding the type of tumour, detailed analysis including immonohistochemistry usually results in accurate histological identification. Although clinical presentation can mimic a malignant process, accurate identification is vital because GIS are relatively benign tumours. As seen in the current case, despite the presence of this lesion at the resection margin, no further surgical intervention was necessary because it was completely excised in the plane of the sections examined. Such coexisting synchronous lesions can cause diagnostic dilemmas that mandate accurate identification in a malignant setting to ensure appropriate oncological management.

AUTHOR CONTRIBUTIONS: All authors participated in the interpretation, design and writing of the manuscript.

COMPETING INTERESTS: The authors declare no competing interests.

ACKNOWLEDGEMENTS: Written consent was obtained from the patient for publication of the present study. 


\section{REFERENCES}

1. Inagawa S, Hori M, Shimazaki J, et al. Solitary schwannoma of the colon: Report of two cases. Surg Today 2001;31:833-8.

2. Matsuki A, Kosugi S, Kanda T, et al. Schwannoma of the esophagus: A case exhibiting high ${ }^{18}$ F-fluorodeoxyglucose uptake in positron emission tomography imaging. Dis Esophag 2009;22:E6-E10.

3. Miettinen M, Blay JY, Sobin LH. Mesenchymal tumours of the stomach. In: Hamilton SR, Aaltonen LA, eds. Pathology and Genetics - Tumours of the Digestive System. Lyon: IARC Press, 2000:62-5.

4. Yoon, HY, Kim CB, Lee YH, Kim HG. Gastric schwannoma. Yonsei Med J 2008;49:1052-4.

5. Prevot S, Bienvenu L, Vaillant JC, de Saint-Maur PP. Benign schwannoma of the digestive tract: A clinicopathologic and immunohistochemical study of five cases, including a case of esophageal tumor. Amer J Surg Path 1999;23:431-6.

6. Abraham S. Distinguishing gastrointestinal stromal tumors from their mimics: An update. Adv Anat Pathol May 2007;14:178-88.

7. Chetty R, Vajpeyi R, Penwick J. Psammomatous melanotic schwannoma presenting as colonic polyps. Virchows Arch 2007;451:717-20

8. Lasota J, Wasag B, Dansonka-Mieszkowska A, et al. Evaluation of NF2 and NF1 tumor suppressor genes in distinctive gastrointestinal nerve sheath tumors traditionally diagnosed as benign schwannomas: A study of 20 cases. Lab Invest 2003;83:1361-71.

9. Fass G, Hossey D, Nyst M, et al. Benign retroperitoneal schwannoma presenting as colitis: A case report. World J Gastroenterol 2007;13:5521-4.

10. Tomozawa S, Masaki T, Matsuda K, Yokoyama T, Ishida T, Muto T. A Schwannoma of the cecum: Case report of Japanese schwannomas in the large intestine. J Gastroenterol 1998;33:872-5.

11. Mulchandani MH, Chattopadhyay D, Obafunwa JO, Joypaul VB. Gastrointestinal autonomic nerve tumours - report of a case and review of literature. World J Surg Onc 2005;3:46.
12. Suster S, Sorace D, Moran CA. Gastrointestinal stromal tumors with prominent myxoid matrix. Clinicopathologic, immunohistochemical, and ultrastructural study of nine cases of a distinctive morphologic variant of myogenic stromal tumor. Am J Surg Pathol 1995;19:59-70.

13. Hong HS, Ha HK, Won HJ, et al. Gastric schwannomas: Radiological features with endoscopic and pathological correlation. Clin Radiol 2000;63:536-42.

14. Pasquini P, Baiocchini A, Falasca L, et al. Mucosal schwann cell "Hamartoma": A new entity? World J Gastroenterol 2009;15:2287-9.

15. Hou YY, Tan YS, Xu JF, et al. Schwannoma of the gastrointestinal tract: A clinicopathological, immunochemical and ultrastructural study of 33 cases. Histopathology 2006;48:536-45.

16. Smith TW, Folkerth RD, Poirier J, Louis DN. Tumors of the Nervous System. In: Gray F, De Girolami U, Poirier J, eds. Escourolle and Poirier. Manual of Basic Neuropathology, 4th edn. Philadelphia: Butterworth Heinemann, 2004:21-56.

17. Heinrich MC, Corless CL, Duensing A, et al. PDGFRA activating mutations in gastrointestinal stromal tumors. Science 2003;299:708-10.

18. Hirota S, Ohashi A, Nishida T, et al. Gain-of-function mutations of platelet-derived growth factor receptor alpha gene in gastrointestinal stromal tumors. Gastroenterology 2003;125:660-7.

19. Steigen SE, Eide TJ. Gastrointestinal stromal tumors (GISTs): A review. APMIS 2009; 117:73-86.

20. Fotiadis C, Kouerinis I, Papandreou I, Zografos G, Agapitos G. Sigmoid schwannoma: A rare case. World J Gastroenterol 2005;11:5079-80.

21. Tozbikian G, Shen R, Suster S. Signet ring cell gastric schwannoma: Report of a new distinctive morphological variant. Ann Diag Pathol 2008; $12: 146-52$.

22. Green TL, Leighty SM, Walters R. Immunohistochemical evaluation of oral myxoid lesions. Oral Surg Oral Med Oral Pathol 1992;73:469-71. 


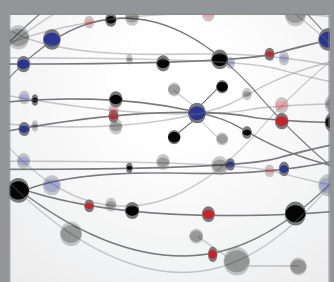

The Scientific World Journal
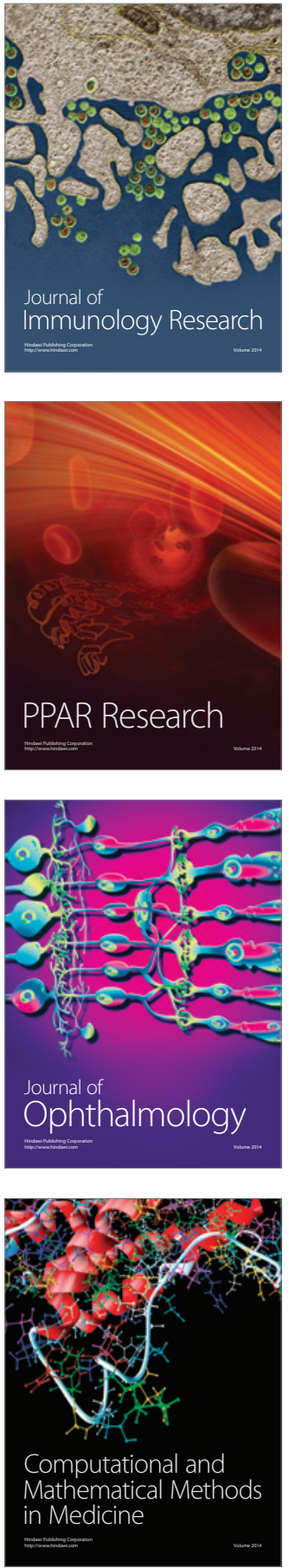

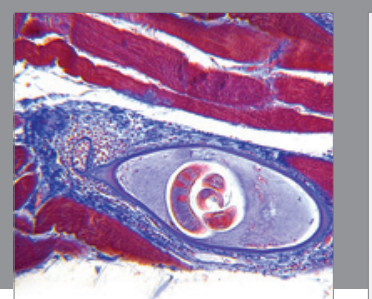

Gastroenterology Research and Practice

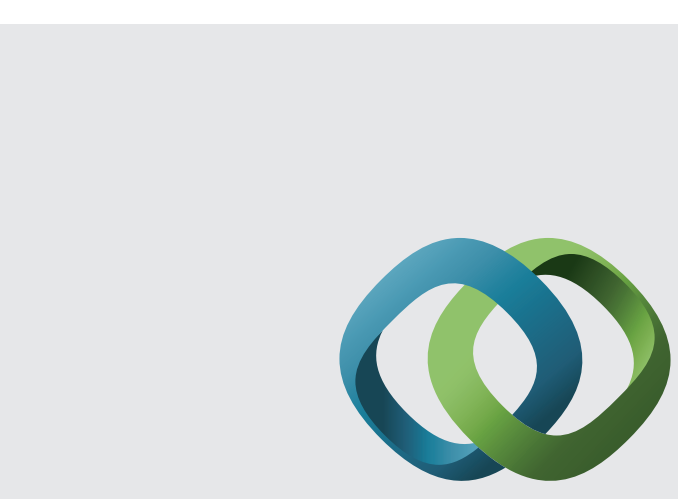

\section{Hindawi}

Submit your manuscripts at

http://www.hindawi.com
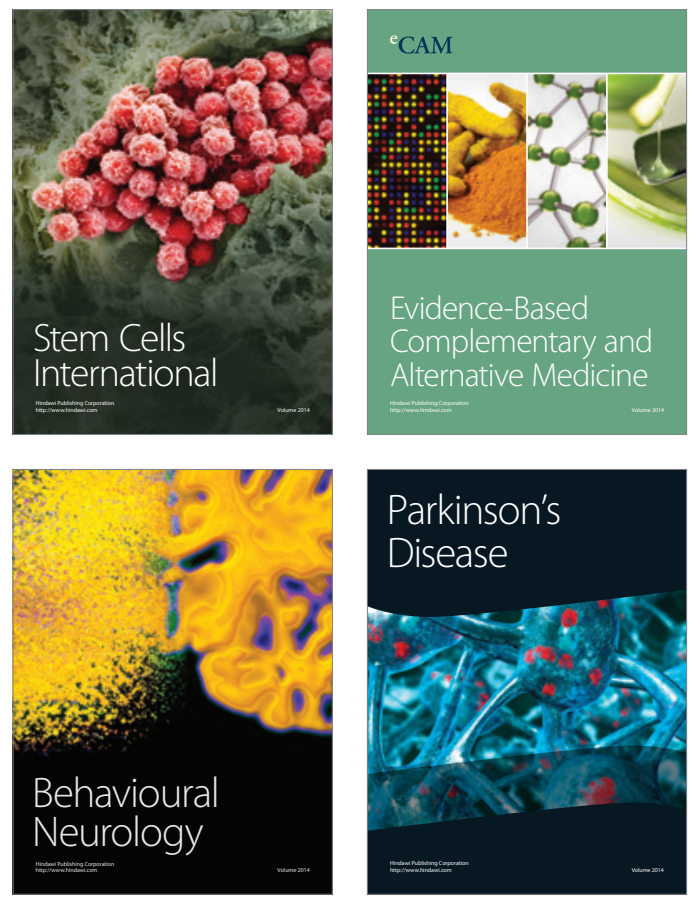
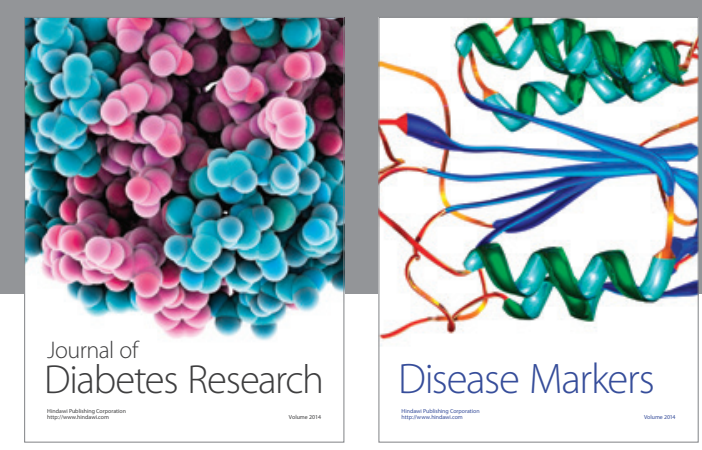

Disease Markers
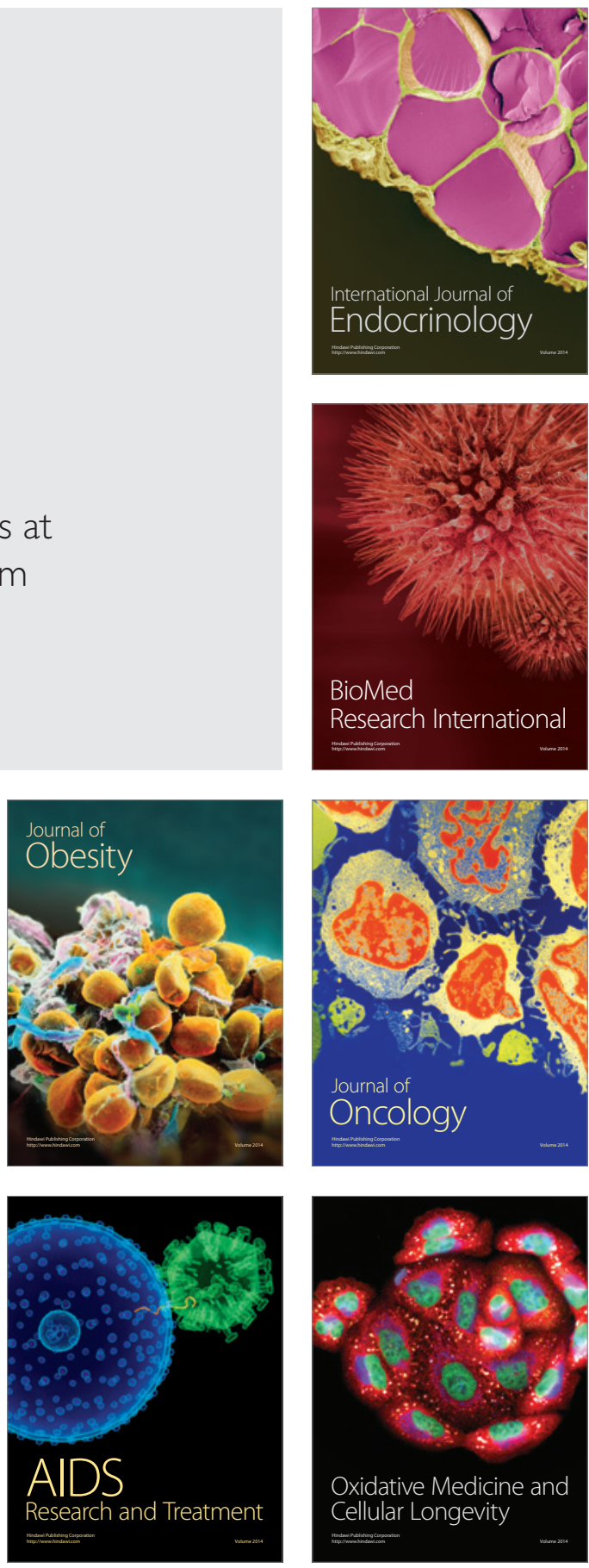